\title{
Article
}

\section{Spectrochemical determination of unique bacterial responses following long-term low-level exposure to antimicrobials}

Jin, Naifu, Semple, Kirk T., Jiang, Longfei, Luo, Chunling, Martin, Francis $L$ and Zhang, Dayi

Available at http://clok.uclan.ac.uk/22011/

Jin, Naifu, Semple, Kirk T., Jiang, Longfei, Luo, Chunling, Martin, Francis L ORCID: 0000-0001-8562-4944 and Zhang, Dayi (2018) Spectrochemical determination of unique bacterial responses following long-term low-level exposure to antimicrobials. Analytical Methods, 10 . pp. 1602-1611. ISSN $1759-9660$

It is advisable to refer to the publisher's version if you intend to cite from the work. http://dx.doi.org/10.1039/c8ay00011e

For more information about UCLan's research in this area go to

http://www.uclan.ac.uk/researchgroups/ and search for <name of research Group>.

For information about Research generally at UCLan please go to http://www.uclan.ac.uk/research/

All outputs in CLoK are protected by Intellectual Property Rights law, including Copyright law. Copyright, IPR and Moral Rights for the works on this site are retained by the individual authors and/or other copyright owners. Terms and conditions for use of this material are defined in the policies page. 
Spectrochemical determination of unique bacterial responses following long-term lowlevel exposure to antimicrobials

$5 \quad{ }^{a}$ Lancaster Environment Centre, Lancaster University, Lancaster LA1 4YQ, UK

$6 \quad{ }^{b}$ School of Environment, Tsinghua University, Beijing 100084, China

$7 \quad{ }^{c}$ Guangzhou Institute of Geochemistry, Chinese Academy of Sciences, Guangzhou 510640,

8 China

$9{ }^{d}$ School of Pharmacy and Biomedical Sciences, University of Central Lancashire, Preston 10 PRI 2HE, UK

$12 *$ Corresponding authors:

13 Francis L Martin, School of Pharmacy and Biomedical Sciences, University of Central 14 Lancashire, Preston PR1 2HE, UK; Email: flmartin@uclan.ac.uk

15 Dayi Zhang, School of Environment, Tsinghua University, Beijing 100084, China; Email: 16 zhangdayi@tsinghua.org.cn 
18 ToC graphic

19

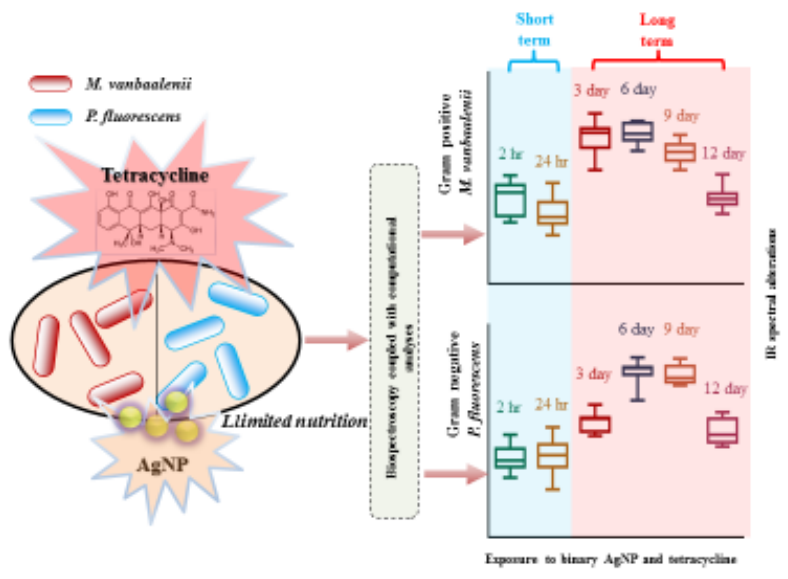

20

21 


\section{Abstract}

23 Agents arising from engineering or pharmaceutical industries may induce significant environmental impacts. Particularly, antimicrobials not only act as efficient eliminators of certain microbes but also facilitate the propagation of organisms with antimicrobial resistance, raising critical health issues, e.g., the bloom of multidrug-resistant bacteria. Although many investigations have examined microbial responses to antimicrobials and characterized relevant mechanisms, they have focused mainly on high-level and short-term exposures, instead of simulating real-world scenarios in which the antimicrobial exposure is at a lowlevel for long periods. Herein, we developed a spectrochemical tool, attenuated total reflection Fourier-transform infrared (ATR-FTIR) spectroscopy, as a high-throughput and nondestructive approach to interrogate the long-term effects of low-level antimicrobial exposure in bacterial cells. Post-exposure to nanoparticulate silver (AgNP), tetracycline or their mixtures for 12 days, Gram-positive (Mycobacterium vanbaalenii PYR-1) and Gramnegative (Pseudomonas fluorescens) bacteria exhibited distinct IR spectral alterations. Multivariate analysis coupled with multivariate regression tree (MRT) indicates nutrient depletion and exposure time as the primary factors in bacterial behaviour, followed by exposure category and bacterial type. Nutrient depletion and starvation during long-term exposure drives bacterial cells into a dormant state or to exhibit additional cellular components (e.g., fatty acids) in response to antimicrobials, consequently causing a broader range of spectral alterations compared to short-term exposure. This work is the first report highlighting the more important roles of exposure duration and nutrient depletion, instead of treatment regimen of antimicrobial, on microbial responses to low-level and prolonged environmental exposures. 


\section{Introduction}

47 Environmental exposure to antimicrobials is a critical issue for both human and microbial communities. Antibiotics are currently ranked as the third most commonly prescribed drugs ${ }^{1}$. In human and veterinary medicine there is abuse of antibiotics, especially for keeping animals healthy at a sub-therapeutic level ${ }^{2-9}$. The primary sink for such antibiotic usage is the environment, e.g., waters and soils, via various pathways post-excretion ${ }^{2,3}$ 4, 6 . Another group of frequently-used antimicrobial agents is silver-associated entities. Notably, unlike silver ion or salts whose antimicrobial effects are well-studied, the mechanisms of nanoparticulate silver (AgNP) activity remain unclear. However, AgNP is widely exploited for its antibacterial activity, in clothing, food containers, wound dressings, ointments, implant coatings, and ultrafiltration membranes for water purification ${ }^{10-14}$. Developing a reliable approach to interrogate microbial responses to antimicrobials is therefore a matter of urgency, contributing to better understanding of the mechanisms and impacts of antimicrobial agents on environmental microbes ${ }^{15}$.

A major issue is the translation from laboratory culture to the real-world scenario of bacteria living in their natural habitats. In contrast to most laboratory culture conditions, e.g., nutrient rich broth, free-living bacteria commonly face nutrient depletion or even more prohibitive circumstances ${ }^{16}$. For instance, cells inhabiting biofilm may be exposed to different concentrations of nutrients, metabolites or environmental stimuli (e.g., temperature, $\mathrm{pH}$, oxygen, etc. $)^{17-21}$ across the biofilm matrix and local microenvironment, leading to heterogeneous growth rates and behaviours amongst the cell populations ${ }^{22,23}$. Amongst these, a small proportion might differentiate into a highly protected phenotypic state and coexist with neighbouring populations that are antibiotic sensitive, resulting from inherent strain differences and adaptation to relatively low concentrations of exposure ${ }^{16,22,23}$. Moreover, although regulatory agencies and pharmaceutical administration generally employs high doses of antimicrobials in in-vivo and in-vitro trials to ensure the safety of test chemicals, residual exposure is typically associated with extremely low-levels in the physical environment; this raises question as to whether high-concentrations of exposure represent the real-world outcomes ${ }^{24-29}$. Thus, research on prolonged low-level exposures of antimicrobials is required in order to shed deeper insights into microbial responses to antimicrobials in the real-world environment ${ }^{15}$. 
Despite recently developed molecular techniques towards targeting microbial phenotypes, such approaches to identify minor or pre-stage phenotypic alterations induced by low-level exposure remain limited ${ }^{30-33}$. Meanwhile, other confounding factors (e.g., microbial species, growth phase, exposure time, etc.) may also influence test results ${ }^{16,31,34}$. In 1991, Fourier-transform infrared (FTIR) spectroscopy was innovatively introduced as a sensitive and rapid screening tool for the characterization, classification and identification of microorganisms ${ }^{16}$. Since then, the emerging application of spectrochemical techniques with computational analysis as an inter-discipline approach shows promising feasibility in microbiology and cytology ${ }^{30-36}$. In the last decade, FTIR spectroscopy plus chemometrics has been exploited broadly for identifying microbial identities, physiologies, activities and related functions ${ }^{16,30,31,33,34,37,38}$. This technical combination provides a major advantage in terms of being high-throughput, label-free and cost-effective in application ${ }^{30}$, allowing one to interrogate biological samples via a nondestructive and nonintrusive manner, which has great potential in monitoring real-world scenarios ${ }^{30-32,34}$.

The current study applied attenuated total reflection FTIR (ATR-FTIR) microscopy coupled with multivariate analysis to investigate bacterial responses to prolonged low-level exposures of AgNP and tetracycline under nutrient depletion conditions. Compared to shortterm exposure, we found that length of exposure plays a more important role than treatment with antimicrobial reagents or bacterial type, further uncovering key influential factors of bacterial responses to antimicrobials during cell growth associated with nutrient depletion.

\section{Methodology}

\subsection{Cell strains and sample preparation}

The two bacterial strains used in this study were Mycobacterium vanbaalenii PYR-1 (Grampositive; originally isolated by Carl E Cerniglia and stored in the culture collection https://www.dsmz.de/catalogues/details/culture/DSM-7251.html) and Pseudomonas fluorescens (Gram-negative; originally isolated in the laboratory of Kirk T Semple at Lancaster University and gifted for purposes of this study). They were both grown in minimal medium with $20 \mathrm{mM}$ sodium succinate, undertaken in a dark rotary shaker at $150 \mathrm{rpm}$ and the culture temperature was $30 \pm 2^{\circ} \mathrm{C}$. After centrifugation and washing with sterile water, cell pellets were diluted in fresh minimal medium with $20 \mathrm{mM}$ sodium succinate and cultivated for about $2 \mathrm{~h}$ until they reached the early $\log$-phase $\left(\mathrm{CFU}=1 \times 10^{7}\right.$ cells $\left./ \mathrm{mL}\right)$. The four treatments included non-exposure negative control (CK), $4 \mu \mathrm{g} / \mathrm{L}$ of $\mathrm{AgNP}, 1 \mu \mathrm{g} / \mathrm{L}$ of 
tetracycline, and a mixture with $4 \mu \mathrm{g} / \mathrm{L}$ of $\mathrm{AgNP}$ and $1 \mu \mathrm{g} / \mathrm{L}$ of tetracycline (Binary). The concentrations of AgNP and tetracycline were selected according to their previous reported level in natural environment to mimic the low-level exposure in real-world scenario ${ }^{38}$. They are about 2-4 orders of magnitude lower than the minimum inhibitory concentration (MIC) of $\operatorname{AgNP}(1 \text { to } 10 \mathrm{mg} / \mathrm{L})^{39,40}$ and tetracycline $(1 \text { to }>30 \mathrm{mg} / \mathrm{L})^{41,42}$, and therefore do not inhibit bacterial growth. The samples of short-term exposure were taken after $2 \mathrm{~h}$ (late log-phase, $\mathrm{T}_{0}$ ) and $48 \mathrm{~h}\left(\mathrm{~T}_{1}\right)$, respectively. To create a nutrient-depletion condition for long-term exposure, the cells were cultivated in 10-times diluted minimal medium and the culture medium was refreshed every $72 \mathrm{~h}$. The samples were collected at $3\left(\mathrm{~T}_{2}\right), 6\left(\mathrm{~T}_{3}\right), 9\left(\mathrm{~T}_{4}\right)$ and $12\left(\mathrm{~T}_{5}\right)$ days. The collected cells were then harvested by centrifugation at $4000 \mathrm{rcf}$ for $5 \mathrm{~min}$, washed three times with sterile deionized water, and finally fixed with $70 \%$ ethanol to prevent further exposure.

\subsection{Spectrochemical analysis}

The prepared samples (minimal amount $>5 \mu \mathrm{L}$ ) were then applied onto Low-E slides and dried for analysis by ATR-FTIR spectroscopy. A Bruker TENSOR 27 FTIR spectrometer (Bruker Optics Ltd., UK) with a Helios ATR attachment containing a diamond internal reflection element (IRE) was applied to acquire IR spectra. The data were attained at a resolution of $3.84 \mathrm{~cm}^{-1}, 2.2 \mathrm{kHz}$ mirror velocity and 32 co-additions. The instrument parameters were set at 32 scans and $16 \mathrm{~cm}^{-1}$ resolution. To collect the data, a total of 30 individual spectral measurements were taken randomly from each sample using the aid of the ATR magnification-limited viewfinder camera. Prior to analysing each new specimen, the crystal was cleaned using deionized water and a background reading was taken.

\subsection{Multivariate analysis and statistics}

All the initial data generated from ATR-FTIR spectroscopy were analysed using MATLAB R2011a (TheMathsWorks, Natick, MA, USA) coupled with the IRootLab toolbox (http://irootlab.googlecode.com $^{43}$. The acquired IR spectra were merged and cut to the biochemical-cell fingerprint region $\left(1800-900 \mathrm{~cm}^{-1}\right)$. Then a rubber-band baseline correction was applied to remove any slopes in this area. The data were then normalized to Amide I $\left(1650 \mathrm{~cm}^{-1}\right)$ and the means were centered allowing alignment of the different spectra for comparison.

Principal component analysis-linear discriminant analysis (PCA-LDA) was applied after data pre-processing to reduce the number of spectra to 10 uncorrelated principal 
components (PCs), which account for $>99 \%$ of the total variance. LDA is a suprevised technique coupled with PCA in order to maximize interclass and minimize intraclass varance $^{30,31,44}$. Cross-calculation was subsequently performed to mitigate risks resulting from LDA overfitting ${ }^{45}$. The PCA-LDA loadings using $(n-1)$ samples $(n=$ number of samples in dataset) was trained via leave-one-out cross-validation and then calculated the scores of the rest sample. This process was performed for all scores within the test.

PCA-LDA cluster vectors are pseudo-spectra highlighting the key biochemical alterations of each group in the datase ${ }^{35}$, which allows one to simplify the identification of discriminating differences amongst groups. The centre of the control cluster itself is moved to the origin of the PCA-LDA factor space. The extent of peak deviation away from the origin of the factor space then occurs according to the centre of each corresponding agent-induced cluster, proportional to the discriminating extent of biochemical differences ${ }^{31,45}$. Cluster vectors plots were also applied to indicate the most prominent six significant peaks.

Multivariate regression trees (MRT) were used to analyse the influence of bacterial type, exposure time and exposure category on biospectral alterations using the $\mathrm{R}$ package "mvpart". Herein, Gram-positive (M. vanbaalenii) and Gram-negative (P. fluorescens) strains were assigned as 1 and 0 . The exposure of AgNP, tetracycline and their mixtures were assigned as 1, 2 and 3, respectively. The samples collected at different time points $\left(T_{0}, T_{1}, T_{2}\right.$, $\mathrm{T}_{3}, \mathrm{~T}_{4}$ and $\mathrm{T}_{5}$ ) were assigned to $1,2,3,4,5$ and 6 , respectively.

One-way analysis of variance (ANOVA) with Tukey's post-hoc test/or $t$-test was employed to test the differences between treatments. All statistical analyses were carried out in GraphPad Prism 6.

\section{Results and discussion}

\subsection{Growth-dependent spectrochemical alterations}

Throughout the study, a spectral class mean for the bacterial control group has been derived, which generates an average spectrum based on all raw data from the same group. However, minor variability is visualised from the class mean data directly between groups at different time points (Figure 1A and 1B). Although previous studies suggest that bacteria with limited nutrients are more likely to enter a dormant state waiting suitable growth conditions ${ }^{46,47}$, the spectral alterations induced by nutrient depletion are limited. Therefore, a further cluster vectors analysis is applied to highlight the minor alterations derived from nutrient depletion 
172 (Figure 1C and 1D). The identical spectral biomarkers in both Gram-positive (M. Vanbaalenii) and Gram-negative (P. fluorescens) bacteria are associated with Amide I, Amide III ( 1204 $\left.\mathrm{cm}^{-1}, \sim 1647 \mathrm{~cm}^{-1}\right)^{30,33}$ (Table 1). The main changes appearing in M. Vanbaalenii are Amide III, $\left(\sim 1204 \mathrm{~cm}^{-1}, \sim 1400 \mathrm{~cm}^{-1}\right), \mathrm{C}=\mathrm{N}$ adenine $\left(\sim 1574 \mathrm{~cm}^{-1}\right)$, Amide $\mathrm{I}\left(\sim 1652 \mathrm{~cm}^{-1}\right)$, and $\mathrm{C}=\mathrm{O}$ band $\left(\sim 1725 \mathrm{~cm}^{-1}\right)^{33,48}$. Of these, the amino acid-associated alterations possibly contributing to nucleotide metabolism, which is important for cellular catabolism are significant. Along with long-term starvation and oxygen depletion, decreasing amounts of nucleotides are associated with reduced cell activities and replication compared to log-phase. Furthermore, alterations in other cellular components (e.g., proteins) might be mainly responsible for cell wall maintenance, based on previous study ${ }^{49}$.

The specific spectrochemical alterations of $P$. fluorescens include Amide III ( 1278 $\left.\mathrm{cm}^{-1}\right), \mathrm{CH}_{2}$ bending of the methylene chains in lipids $\left(\sim 1470 \mathrm{~cm}^{-1}\right)$, protein Amide II absorption $\left(\sim 1540 \mathrm{~cm}^{-1}\right), \mathrm{C}=\mathrm{N}$ cytosine $\left(\sim 1601 \mathrm{~cm}^{-1}\right), v(\mathrm{C}=\mathrm{C})$ lipids, and fatty acids $(\sim 1750$ $\left.\mathrm{cm}^{-1}\right)^{34,48}$. Accordingly, more lipid alterations under nutrient depletion conditions are found in Gram-negative P. fluorescens versus Gram-positive M. vanbaalenii owing to their differing cell wall structures. There is only a thin peptidoglycan layer $(\sim 2-3 \mathrm{~nm})$ between the cytoplasmic and outer membrane in Gram-negative bacteria, whereas the outer membrane in Gram-positive bacteria is a thick peptidoglycan layer of $30 \mathrm{~nm}$ with no other additional structure $^{50}$. The attributes of membrane structure may explain the distinct spectrochemical alterations between $P$. fluorescens and $M$. vanbaalenii under nutrient depletion, which might lead to different responses towards long-term exposure of antimicrobials. 
(A)

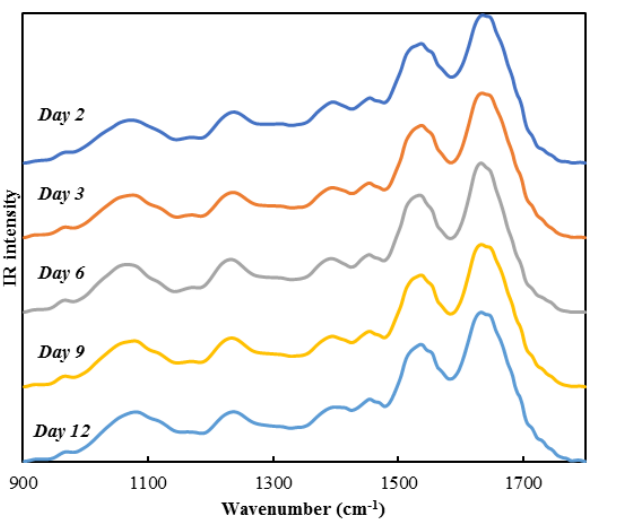

(C)

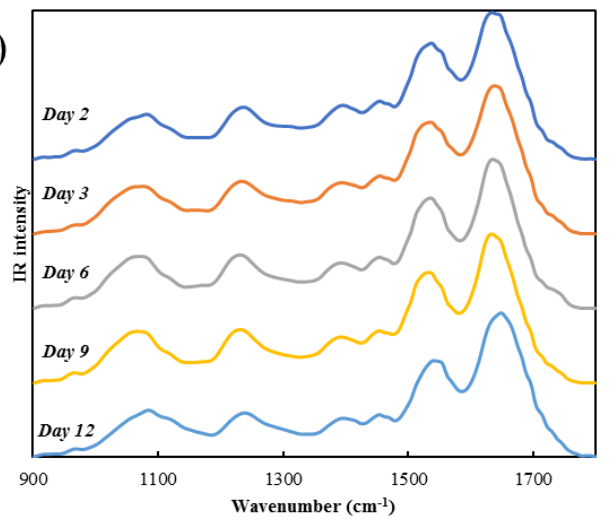

(B)

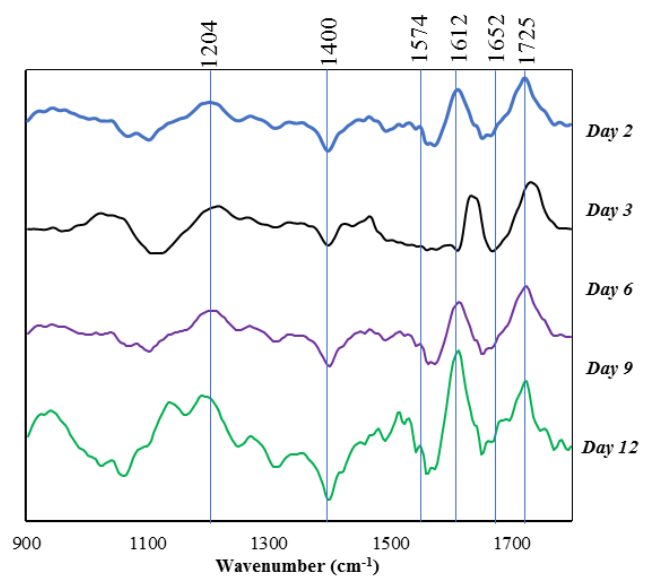

(D)

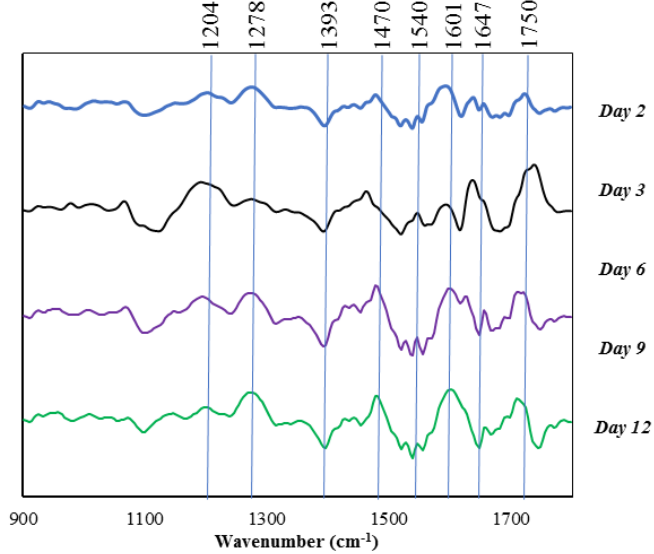

Figure 1. Spectrochemical alterations with length of culture. Infrared spectra of $M$. vanbaalenii (A) and P. fluorescens (C) from control group. Cluster vectors plots of $M$. culture time. 
Table 1. Spectrochemical profile regarding the significant spectral biomarkers peaks derived from cluster vectors of M. vanbaalenii (Grampositive) and P. fluorescens (Gram-negative) post-exposure to AgNP, tetracycline and their mixtures. Red dots represent identical biomarkers for both Gram-positive and Gram-negative bacteria, and green and blue dots indicate biomarkers appear only in Gram-positive or Gram-negative bacteria, respectively.

\begin{tabular}{|c|c|c|c|c|c|c|c|c|c|}
\hline \multirow{2}{*}{$\begin{array}{l}\text { Wavenumber } \\
\left(\mathrm{cm}^{-1}\right)\end{array}$} & \multirow{2}{*}{ Annotation } & \multicolumn{4}{|c|}{ Gram-positive } & \multicolumn{4}{|c|}{ Gram-negative } \\
\hline & & Growth & AgNP & Tetracycline & Binary & Growth & $\mathrm{AgNP}$ & Tetracycline & Binary \\
\hline$\sim 1084$ & DNA & - & - & $\bullet$ & $\bullet$ & - & - & - & - \\
\hline$\sim 1212$ & Phosphate & - & - & - & - & - & - & - & - \\
\hline$\sim 1220$ & $\begin{array}{c}\mathrm{PO}_{2}^{-} \text {stretching in RNA and } \\
\text { DNA }\end{array}$ & - & - & $\bullet$ & $\bullet$ & - & - & • & - \\
\hline$\sim 1327$ & Stretching $\mathrm{C}-\mathrm{N}$ thymine, adenine & - & - & - & - & - & $\bullet$ & - & • \\
\hline$\sim 1393$ & & - & - & - & - & - & - & - & - \\
\hline$\sim 1400$ & & $\bullet$ & - & - & - & - & - & - & - \\
\hline$\sim 1404$ & $\mathrm{CH}_{3}$ asymmetric deformation & - & - & - & - & - & - & - & - \\
\hline$\sim 1423$ & & - & - & - & - & - & $\bullet$ & $\bullet$ & • \\
\hline$\sim 1458$ & Lipids and proteins & - & - & - & - & - & - & $\bullet$ & - \\
\hline$\sim 1520$ & Amide II & - & - & - & - & - & - & - & $\bullet$ \\
\hline$\sim 1540$ & Protein amide II absorption & - & - & - & - & $\bullet$ & - & - & - \\
\hline$\sim 1555$ & Ring base & - & $\bullet$ & • & $\bullet$ & - & - & - & - \\
\hline$\sim 1574$ & $\mathrm{C}=\mathrm{N}$ adenine & $\bullet$ & - & - & - & - & - & - & - \\
\hline$\sim 1577$ & C-C stretch & - & - & - & - & - & $\bullet$ & - & - \\
\hline
\end{tabular}




\begin{tabular}{|c|c|c|c|c|c|c|c|c|c|}
\hline$\sim 1601$ & $\mathrm{C}=\mathrm{N}$ cytosine & - & - & - & - & $\bullet$ & - & - & - \\
\hline$\sim 1612$ & & - & - & - & - & - & - & - & - \\
\hline$\sim 1624$ & & - & - & - & - & - & $\bullet$ & - & - \\
\hline$\sim 1632$ & C-C stretch & - & - & - & $\bullet$ & - & - & - & - \\
\hline$\sim 1639$ & Amide & - & - & - & - & - & - & $\bullet$ & - \\
\hline$\sim 1647$ & Amide I & - & - & $\bullet$ & - & $\bullet$ & - & - & - \\
\hline$\sim 1652$ & Amide I & $\bullet$ & - & - & - & - & - & - & - \\
\hline$\sim 1666$ & $\begin{array}{c}\mathrm{C}=\mathrm{O} \text { stretching vibration of } \\
\text { pyrimidine base }\end{array}$ & - & - & - & - & - & $\bullet$ & - & - \\
\hline$\sim 1670$ & Amide I & - & $\bullet$ & - & - & - & - & - & - \\
\hline 1694 & Proteins & - & - & - & - & - & - & $\bullet$ & - \\
\hline$\sim 1706$ & $\mathrm{C}=\mathrm{O}$ thymine & - & $\bullet$ & - & - & - & - & - & - \\
\hline$\sim 1725$ & $\mathrm{C}=\mathrm{O}$ band & $\bullet$ & - & - & - & - & - & - & - \\
\hline$\sim 1740$ & $\mathrm{C}=\mathrm{O}$, lipids & - & - & - & - & - & - & $\bullet$ & $\bullet$ \\
\hline$\sim 1750$ & $v(C=C)$ lipids, fatty acids & - & - & $\bullet$ & - & $\bullet$ & - & - & - \\
\hline
\end{tabular}


205 To identify exposure-induced alterations, the spectral data of each treatment group are compared with the control group at the same time point, eliminating the impacts of cell growth and nutrient depletion (Figure 2). In Gram-positive M. Vanbaalenii, the AgNPinduced alterations are C-C, C-O deoxyribose $\left(\sim 964 \mathrm{~cm}^{-1}\right)$, phosphate $\left(\sim 1212 \mathrm{~cm}^{-1}\right)$, Amide III $\left(\sim 1307 \mathrm{~cm}^{-1}\right)$, ring base $\left(\sim 1555 \mathrm{~cm}^{-1}\right)$, Amide $\mathrm{I}\left(\sim 1670 \mathrm{~cm}^{-1}\right)$, and $\mathrm{C}=\mathrm{O}$ thymine $(\sim 1706$ $\left.\mathrm{cm}^{-1}\right)^{30,33,38}$. Post-exposure to tetracycline, the representative peaks are DNA $\left(\sim 1084 \mathrm{~cm}^{-1}\right)$,

$211 \mathrm{PO}_{2}^{-}$stretching in RNA and DNA $\left(\sim 1220 \mathrm{~cm}^{-1}\right)$, ring base $\left(\sim 1555 \mathrm{~cm}^{-1}\right)$, Amide I $(\sim 1647$

$\left.212 \mathrm{~cm}^{-1}\right)$, lipids, and fatty acids $\left(\sim 1750 \mathrm{~cm}^{-1}\right)^{33,38,48}$. With the binary exposure, the alterations are different from individual exposures, and the specific spectral biomarkers are DNA $(\sim 1084$ $\left.\mathrm{cm}^{-1}\right), \mathrm{PO}_{2}^{-}$stretching in RNA and DNA $\left(\sim 1220 \mathrm{~cm}^{-1}\right)$, Amide III $\left(\sim 1307 \mathrm{~cm}^{-1}\right), \mathrm{CH}_{3}$ asymmetric deformation $\left(\sim 1404 \mathrm{~cm}^{-1}, \sim 1462 \mathrm{~cm}^{-1}\right)$, ring base $\left(\sim 1555 \mathrm{~cm}^{-1}\right)$, and C-C stretch

$216\left(\sim 1632 \mathrm{~cm}^{-1}\right)^{38,48}$. It is worth mentioning that the binary effects of AgNP and tetracycline on

217 M. vanbaalenii spectra are mainly driven by tetracycline as more identical discriminating

218 peaks are observed between these two groups (Table 1). To evaluate the impacts of each exposure, PCA-LDA score plots were generated and illustrate the increasing segregation between groups with increasing exposure time (from day 3 to day 12, Figure 3). Particularly, the biochemical distances of tetracycline and binary groups are co-located, apparently separated from the control group and markedly on day 12. However, the AgNP-treated groups only show slight shifting of biochemical differences compared to the control group.

224 This result is consistent with cluster vectors analysis that the binary-exposure effects in $M$. vanbaalenii are closer to tetracycline alone than AgNP. 

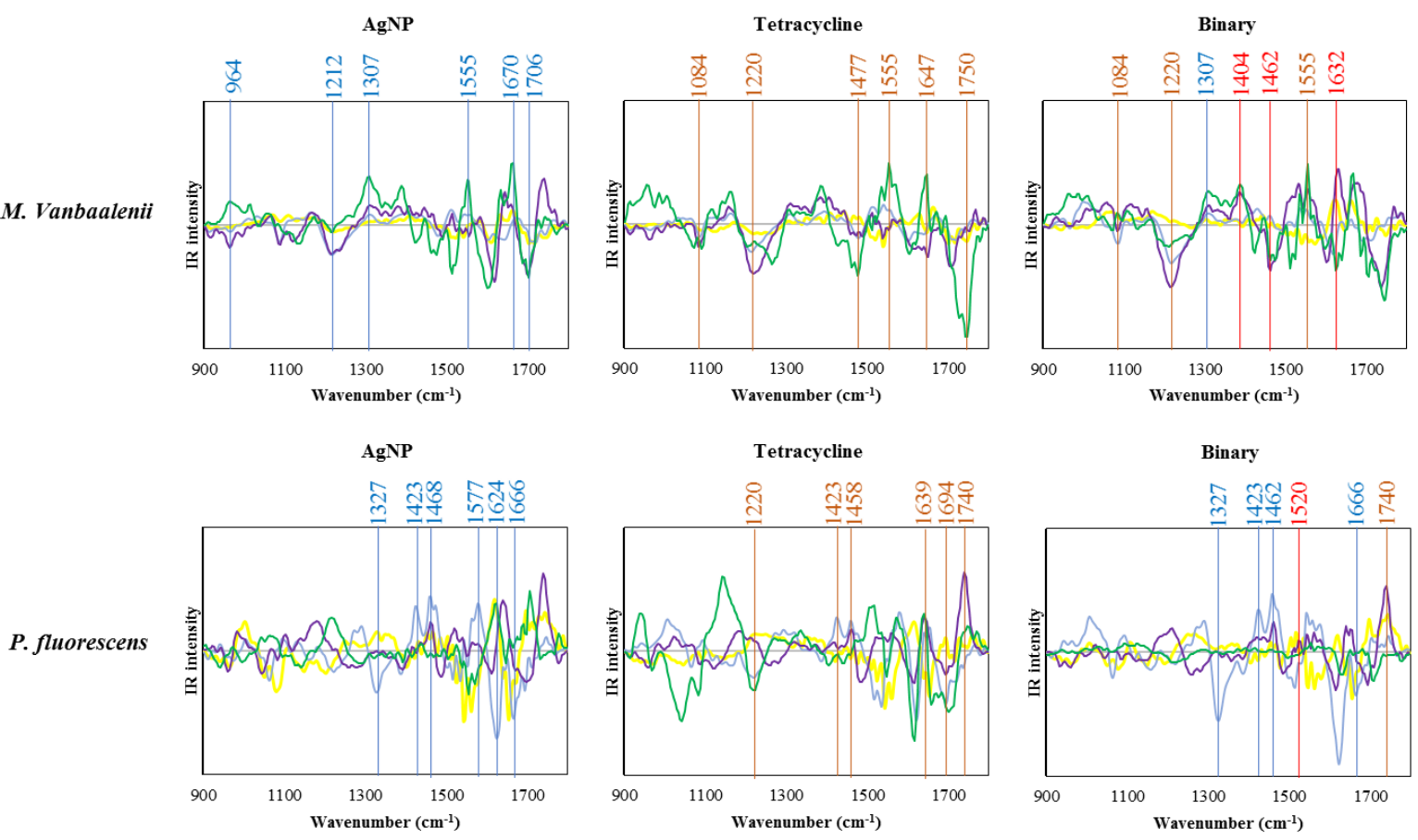

227 Figure 2. Cluster vectors plots after PCA-LDA, indicating significant wavenumbers for the segregation of $M$. vanbaalenii and $P$. fluorescens following long-term exposure (day 3 to day 12) to AgNP, tetracycline or their mixtures.

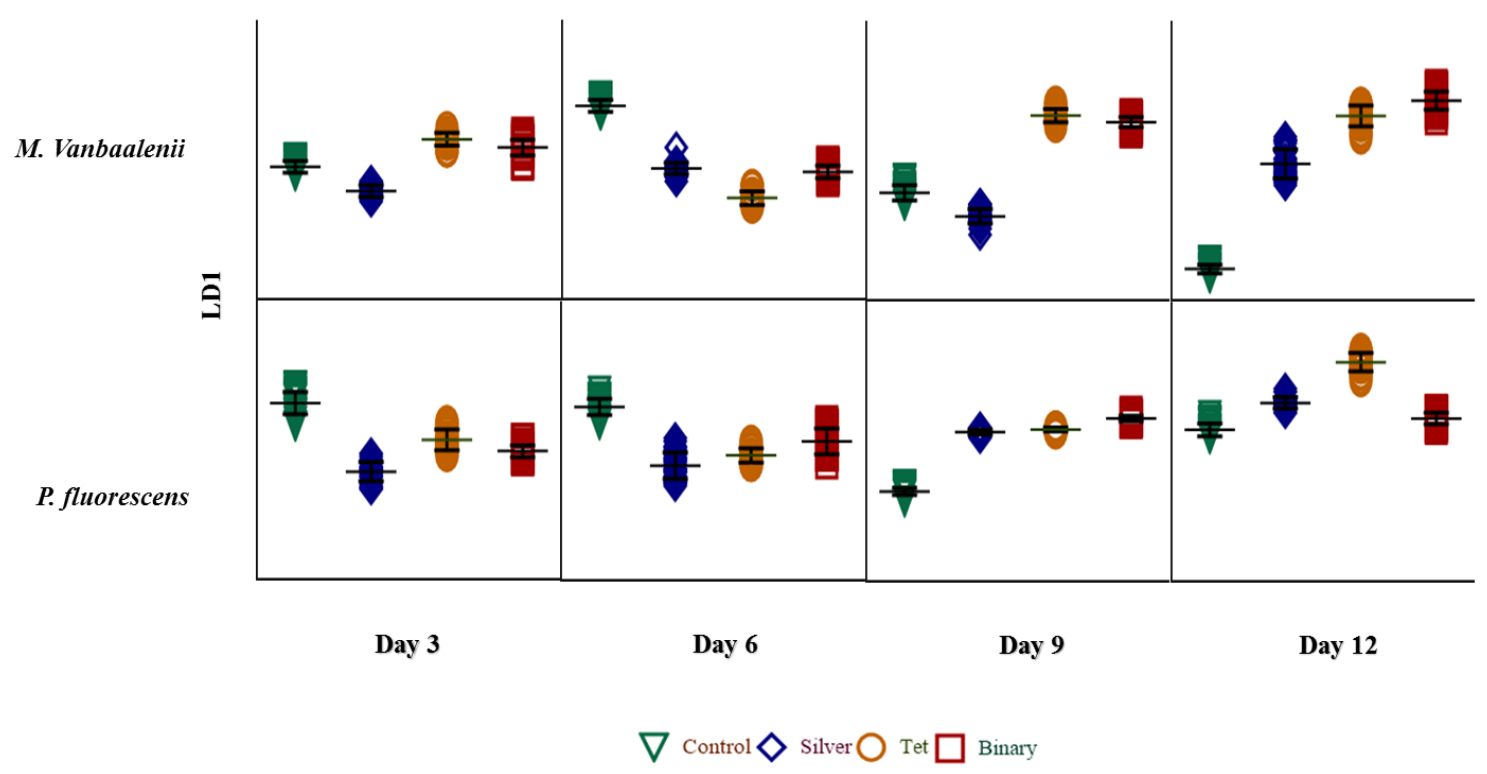

Figure 3. PCA-LDA score plots for the biospectral alteration of $M$. vanbaalenii and $P$.

233 fluorescens following long-term exposure (day 3 to day 12) to AgNP, tetracycline or their 234 mixtures. 
In Gram-negative P. fluorescens, all the exposure groups are clearly separated from the control group in the PCA-LDA score plots (Figure 3), and there is no significant difference between each treatment. The AgNP-induced alterations include stretching C-N thymine, adenine $\left(\sim 1327 \mathrm{~cm}^{-1}\right)$, lipids and proteins $\left(\sim 1458 \mathrm{~cm}^{-1}\right)$, C-C stretch $\left(\sim 1577 \mathrm{~cm}^{-1}\right),(\sim 1624$ $\left.\mathrm{cm}^{-1}\right)$, and $\mathrm{C}=\mathrm{O}$ stretching vibration of pyrimidine base $\left(\sim 1666 \mathrm{~cm}^{-1}\right)^{48}$. The tetracyclineinduced peaks are DNA $\left(\sim 1220 \mathrm{~cm}^{-1}\right) ;\left(\sim 1423 \mathrm{~cm}^{-1}\right)$, collagen $\left(\sim 1458 \mathrm{~cm}^{-1}\right)$, Amide I $(\sim 1639$ $\left.\mathrm{cm}^{-1}, \sim 1694 \mathrm{~cm}^{-1}\right)$, and $\mathrm{C}=\mathrm{O}$ lipids $\left(\sim 1740 \mathrm{~cm}^{-1}\right)^{38,48}$. Generally, outer cellular components are widely affected by both AgNP and tetracycline, including Amides I/II and proteins $\left(\sim 1307 \mathrm{~cm}^{-1}, \sim 1647 \mathrm{~cm}^{-1}, 1639-1694 \mathrm{~cm}^{-1}\right)$, and lipids and/or fatty acids $\left(1750 \mathrm{~cm}^{-1}, 1458\right.$ $\left.\mathrm{cm}^{-1}, 1740 \mathrm{~cm}^{-1}\right)^{30,33,38,48}$, indicating that the cell membrane is the primary reactive target associated with both antimicrobials which penetrate bacterial cells via passive diffusion and inhibit bacterial growth by perturbing protein synthesis or altering membrane structure ${ }^{51}$. Additionally, more inner cellular components are identified to be associated with tetracycline exposure than AgNP, e.g., inherent DNA and RNA, possibly due to the antibiotic mechanism of tetracycline which blocks the elongation cycle by preventing incoming aminoacyl-tRNA (aa-tRNA) from binding to the ribosomal A-site and inhibiting protein synthesis ${ }^{52}$. Different from Gram-positive strains, AgNP-induced alterations contribute predominantly to the binary effects in P. fluorescens, i.e., stretching C-N thymine, adenine $\left(\sim 1327 \mathrm{~cm}^{-1}, \sim 1423 \mathrm{~cm}^{-1}\right.$, $\left.\sim 1462 \mathrm{~cm}^{-1}\right)$, Amide II $\left(\sim 1520 \mathrm{~cm}^{-1}\right), \mathrm{C}=\mathrm{O}$ stretching vibration of pyrimidine base $(\sim 1666$ $\left.\mathrm{cm}^{-1}\right)$, and $\mathrm{C}=\mathrm{O}$ lipids $\left(\sim 1740 \mathrm{~cm}^{-1}\right)^{31,34}$. These findings imply the antimicrobial synergism of AgNP and tetracycline. A previous study suggests that antibiotics' efficacy against microbes may increase in the presence of AgNP because of the bonding reaction between antibiotics and nanofillers, owing to the chelating reaction of hydroxyl and amide groups in antibiotic molecules with $\mathrm{AgNP}^{53}$.

\subsection{Impacts of exposure time on spectrochemical alterations}

Although short-term impacts by antimicrobials on bacteria is obvious and well-studied, their consequences may last for extended periods and remain unknown ${ }^{54}$. To unravel such longterm exposure effects, we measured the biospectral alterations at different time points, and found distinguishing biomarkers post-exposure to antimicrobials between short-term versus long-term treatments (Figure 4). Generally, in short-term exposure ( $\leq 3$ days), spectral changes are associated with components from cell membranes wherein most antimicrobialinduced alterations occur in both strains, including glycogen $\left(\sim 1022 \mathrm{~cm}^{-1}\right)$, symmetric phosphate stretching vibrations $\left(\nu_{\mathrm{s}} \mathrm{PO}_{2}^{-} ; \sim 1088 \mathrm{~cm}^{-1}, 1092 \mathrm{~cm}^{-1}\right)$, carbohydrates $(\sim 1165$ 
$\left.\mathrm{cm}^{-1}\right)$, protein phosphorylation $\left(\sim 964 \mathrm{~cm}^{-1}\right)$, Amide I $\left(\sim 1609 \mathrm{~cm}^{-1}, 1612 \mathrm{~cm}^{-1}, 1659 \mathrm{~cm}^{-1}\right.$, $\left.\sim 1670 \mathrm{~cm}^{-1}\right)$, Amide III $\left(\sim 1269 \mathrm{~cm}^{-1}\right)$, COO- symmetric stretching vibrations of fatty acids and amino acid $\left(\sim 1408 \mathrm{~cm}^{-1}\right)$, proteins $\left(\sim 1485 \mathrm{~cm}^{-1}, \sim 1550 \mathrm{~cm}^{-1}, \sim 1650 \mathrm{~cm}^{-1}\right)$, and lipids $\left(\sim 1701 \mathrm{~cm}^{-1}, 1705-1750 \mathrm{~cm}^{-1}\right)^{30,32,38,48}$. Besides external cellular components, some inherent elements are significantly influenced in long-term exposure ( $>3$ days). For instance, long-term tetracycline-induced alterations in P. fluorescens include RNA and DNA (e.g., $\sim 1220 \mathrm{~cm}^{-1}, \sim 1423 \mathrm{~cm}^{-1}$ ). Compared to prolonged exposure, short exposure induces minimal alterations, possibly owing to bacteria undergoing pre-stage reactions against antimicrobials. During extended exposure periods, the more obvious biospectral alterations might be explained by increasing tetracycline accumulation via penetration and stronger antibiotic effects, which prevent RNA binding to the ribosomal A-site and protein synthesis ${ }^{52}$, and further inhibit RNA/DNA synthesis and duplication ${ }^{55}$. Another explanation is the postantibiotic effect (PAE) or lag of bacterial regrowth induced by long-term antimicrobial exposure, driving bacterial entry into a growth suppression state ${ }^{56,57}$.

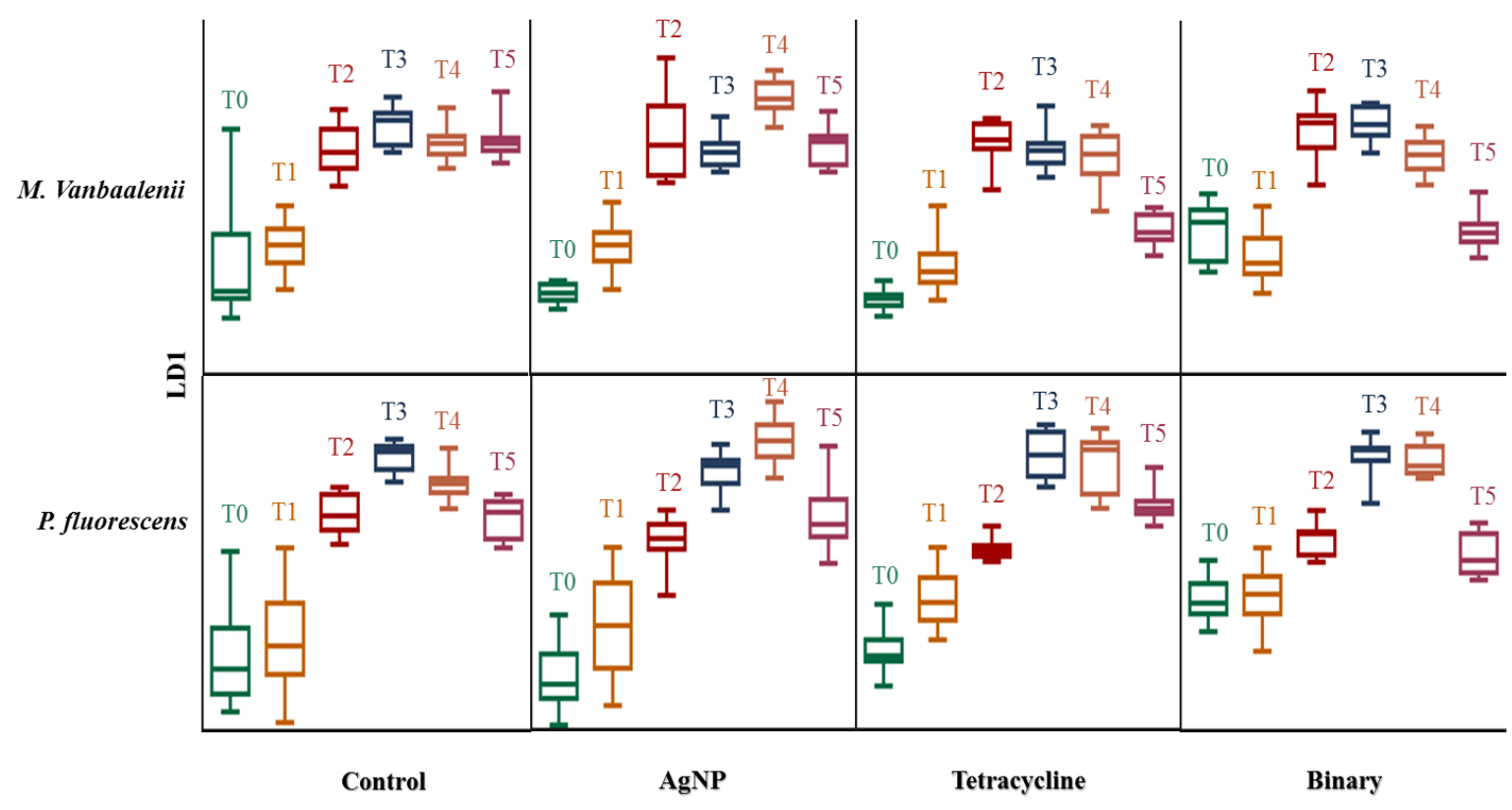

Figure 4. PCA-LDA score plots of the biospectral alteration of $M$. vanbaalenii and $P$. fluorescens in both short-term and long-term exposure to AgNP, tetracycline and their mixtures. $\mathrm{T}_{0}, \mathrm{~T}_{1}, \mathrm{~T}_{2}, \mathrm{~T}_{3}, \mathrm{~T}_{4}$ and $\mathrm{T}_{5}$ represent exposure time of $2 \mathrm{~h}, 2$ days, 3 days, 6 days, 9 days and 12 days, respectively. 
Although distinct impacts of different antimicrobials on bacteria have been well-documented, many variables including intrinsic and external factors may alter such influences in realworld scenarios. In the present study, we evaluated bacterial type, exposure category, exposure time and nutrient depletion, but which factor is the most dominating remains unlcear. To answer this question, a multivariate regression trees (MRT) analysis based on isolated discriminating biomarkers is conducted to quantify the impacts of these four factors on spectral alterations. MRT visualizes these influencing factors on spectral variations in a tree with four splits based on exposure time, exposure category, bacterial type and nutrient depletion, explaining $63.7 \%$ of the total spectral variance (Figure 5). Level of influence is ranked as exposure time $>$ exposure type $>$ bacterial type $=$ nutrient depletion. Exposure time accounts for $17.8 \%$ of the total variance, with the first split separating the group of 12-day exposure owing to the relatively lower intensities of DNA. In the 12-day exposure group, exposure category explains $16.1 \%$ of the variance and splits spectra into two groups of control/tetracycline and AgNP/binary, mainly based on DNA spectral biomarkers. The group of exposure $<12$ days is further split by bacterial type, accounting for $14.9 \%$ of the total variance and attributed to differences in DNA, phospholipid-derived fatty acids and proteins. The final split representing nutrient depletion separates the groups of 6-9 day and 0-3 day for Gram-positive bacteria (M. vanbaalenii, 14.9\%), owing to higher cellular activities reflected by significant variations in DNA, phospholipid-derived fatty acids and proteins.

The MRT results are consistent with PCA-LDA score plots (Figure 4). The spectral distances of $P$. fluorescens, for instance, are similar regardless of exposure categories from day 9 due to cell regeneration against the exposure and exhibiting resistance to antimicrobials $^{46}$. A prior study reported that long-term exposure (5 days) to $1 \mu \mathrm{g} / \mathrm{L}$ of tetracycline shows no apparent effect on cyanobacterial cells due to their natural variability in tetracycline resistance ${ }^{58}$. It might explain the closer distance between groups of control and tetracycline. Moreover, the distinct behaviours of $M$. vanbaalenii and P. fluorescens upon starvation can explain the fourth split in MRT, i.e., M. vanbaalenii enters a replicative state after 6-day exposure to adapt to conditions of insufficient nutrients, whereas $P$. fluorescens appears more susceptible to nutrient depletion and starts regrowth. Evidence can be found from the additional collular components produced in Gram-negative P. fluorescens, e.g., fatty acids $\left(\sim 1750 \mathrm{~cm}^{-1}\right)$, as their predominant energy to survive $\mathrm{e}^{46}$. 


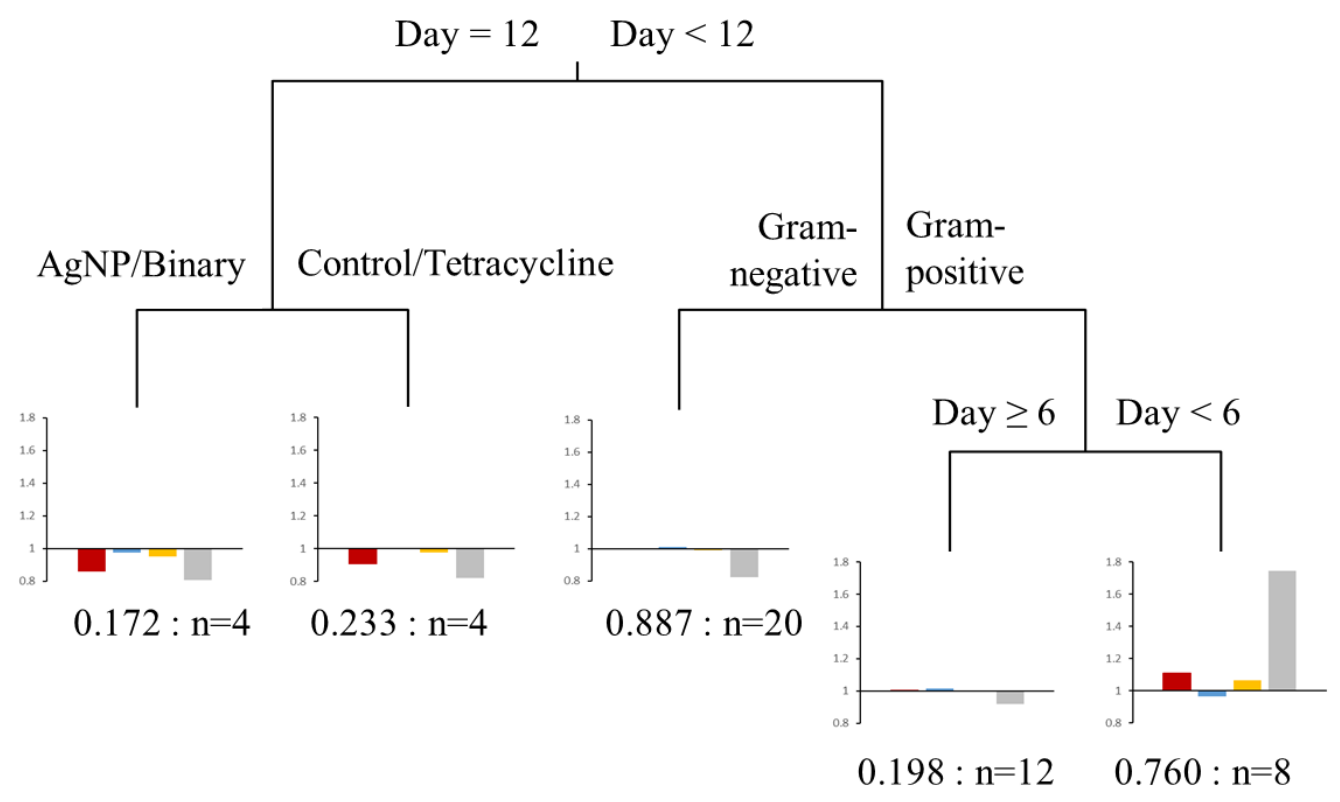

Error: 0.364 CV Error: 0.572 SE: 0.119

321 Figure 5. Multivariate regression tree (MRT) analysis of environmental variables explaining 322 discriminating biomarkers. The scale of the sub-figures reflects the alteration degree (number 323 one represents the average level). Red bars represent biomarkers assigned to DNA; blue bars 324 represent biomarkers associated with proteins; yellow bars represent biomarkers assigned to phospholipid-derived fatty acids; and, grey bars represent other cellular components.

327 Moreover, bacterial type may also have impacts on the consequences posed by antimicrobials 328 since bacteria differ in their cellular structures. Antimicrobials acting as both efficient 329 eliminators to microbes and selective agents help to propagate organisms with resistance ability ${ }^{59}$. Herein, we found discriminating alterations between Gram-positive and Gramnegative strains within the same exposure treatment. All the treatments exhibit distinct alterations in Gram-positive M. vanbaalenii under nutrient depletion conditions (Day 3 to Day 12), although AgNP generates very limited impact as compared to tetracycline or binary exposure groups; these are not observed in P. fluorescens. The results from PCA-LDA scores plots (Figure 3) and MRT (Figure 5) also show induced alterations in M. vanbaalenii are significant compared to P. fluorescens. Furthermore, after long-term exposure (12 days), 
Gram-negative $P$. fluorescens exhibit a broad range of spectral alterations assigned to lipids and/or fatty acid (e.g., $1458 \mathrm{~cm}^{-1}, 1740 \mathrm{~cm}^{-1}$ ), which are absent in Gram-positive $M$. vanbaalenii, mainly attributed to their different cell wall structures. The rigidity and extended cross-linking may reduce the target sites in cell membranes for environmental exposures and afford further protection to cells from antimicrobial penetration ${ }^{12,53}$. It implies that cell membranes of Gram-negative bacteria are more likely to be influenced compared to Grampositive bacteria under certain antibacterial treatments (e.g., AgNP $)^{12,50,60}$. Past studies report the oxidation of smaller AgNPs (1-10 nm) by intercellular reactive oxygen species (ROS) in Gram-negative bacteria, resulting in the release of silver ions during AgNP penetration through the cell membrane and entrance into the cytoplasm ${ }^{60}$. These silver ions could be further transferred to other Gram-negative bacterial cells, the membrane and cytoplasm which contain many sulfur-containing proteins for the released $\mathrm{Ag}^{+}$to bind to and inactivate ${ }^{50,60}$. Furthermore, it has been recognised that heavy metal treatment can induce global biomolecular changes in lipids and proteins, implying exotic exposure may lead to the development of relevant metabolic changes in cellular components, particularly the membrane ${ }^{61-63}$. A recent study, for instance, reported that Ag exposure could increase cellular lipid contents while decrease membrane fluidity ${ }^{61}$, and the possible mechanism is upregulated lipid biosynthesis, which is known to be associated with the reduced membrane permeability.

Besides bacterial type, exposure time and exposure category, nutrient depletion is also found to be an influential factor in the bacterial antimicrobial response. Here, bacterial cells tend to adapt to new environmental stimuli after entering into a long-term nutrient-deprived situation. From the cluster vectors analysis (Figure 1), spectral alterations in both strains from Day 6 show slight peak shifts, which can be regarded as a potential signal showing that bacterial cells are undergoing adaption. Additionally, $M$. vanbaalenii becomes a persistent suspension in the media on entering a dormant state from Day 6. This is because bacteria in a non-growing state can survive for much longer time under conditions of reduced oxygen or nutrient deprivation ${ }^{46,47}$. Upon starvation, bacterial cells fragment into small spheroids exhibiting rapid and drastic decreases in endogenous metabolism. This reorganization gives bacteria maximum survival during long-term starvation. Specifically, bacteria on starvation initially induce dwarfing generating cell number increases via fragmentation over the first 1 to $2 \mathrm{~h}$ and continuous size reductions in the fragmented cells, but no further increase in numbers. After dwarfing phases, cell size continues to get smaller, with little or no metabolic activity, and slow loss of viability ${ }^{64}$. It has been reported that non-growing phase bacteria 
adapt to and increase their tolerance to environmental stresses and such developed persistent bacilli are capable of surviving several months of combinatorial antibiotic treatment ${ }^{47}$, which implies that stressed living conditions, to some extent and paradoxically, could help microbial resistance to antimicrobial effects.

\section{Conclusions}

In the present study, we employed spectrochemical analysis coupled with multivariate analysis as a robust tool towards investigating bacterial responses ${ }^{65}$ to long-term and lowlevel exposure of antimicrobials under nutrient depletion conditions. ATR-FTIR spectroscopy shows feasibility in revealing sufficient biochemical information continuously even at extremely low-level exposures in a starvation situation, which fits better with real-world circumstances and the natural state of microcosms. From the multivariate analysis of spectra coupled with MRT, we evaluate the significance of different factors on long-term bacterial responses to antimicrobials and find pivotal roles for exposure time and nutrient depletion. Nutrient depletion can drive bacterial cells to either enter into a dormant state or exhibit extra-cellular components against environmental antimicrobials, consequently causing a broader range of spectral alteration compared to short-term exposures. Differences in bacterial behaviours towards antimicrobials are also found between bacterial types (Grampositive versus Gram-negative) attributed to variations in cell wall structure. Our work is the first revealing of the more important roles of exposure duration and nutrient depletion, rather than of antimicrobial reagents, on microbial responses to low-level and prolonged environmental exposures. We believe this approach has an important future with potential feasibility in in situ screening of environmental exposures in real-time.

\section{Conflicts of interest}

There are no conflicts of interest to declare.

\section{Acknowledgement}

N.J. was funded by Chinese Academy of Sciences and China Scholarship Council. 
400 1. J. Conly, Can. Med. Assoc. J., 2002, 167, 885-891.

2. J. W. Harrison and T. A. Svec, Quintessence Int., 1998, 29, 223-229.

3. J. C. Chee-Sanford, R. I. Aminov, I. J. Krapac, N. Garrigues-Jeanjean and R. I. Mackie, Appl. Environ. Microbiol., 2001, 67, 1494-1502.

4. G. Hamscher, S. Sczesny, H. Hoper and H. Nau, Anal Chem, 2002, 74, 1509-1518.

5. X. L. Ji, Q. H. Shen, F. Liu, J. Ma, G. Xu, Y. L. Wang and M. H. Wu, J. Hazard Mater., 2012, 235, 178-185.

6. L. Cantas, S. Q. A. Shah, L. M. Cavaco, C. M. Manaia, F. Walsh, M. Popowska, H. Garelick, H. Burgmann and H. Sorum, Front. Microbiol., 2013, 4, 14.

7. A. Koluman and A. Dikici, Crit. Rev. Microbiol., 2013, 39, 57-69.

8. M. Tandukar, S. Oh, U. Tezel, K. T. Konstantinidis and S. G. Pavlostathis, Environ. Sci. Technol., 2013, 47, 9730-9738.

9. J. L. Martinez and F. Baquero, Ups. J. Med. Sci., 2014, 119, 68-77.

10. J. S. Kim, E. Kuk, K. N. Yu, J. H. Kim, S. J. Park, H. J. Lee, S. H. Kim, Y. K. Park, Y. H. Park, C. Y. Hwang, Y. K. Kim, Y. S. Lee, D. H. Jeong and M. H. Cho, Nanomed.Nanotechnol. Biol. Med., 2014, 10, 1119-1119.

11. C. N. Lok, C. M. Ho, R. Chen, Q. Y. He, W. Y. Yu, H. Sun, P. K. H. Tam, J. F. Chiu and C. M. Che, J. Biol. Inorg. Chem., 2007, 12, 527-534.

12. H. H. Lara, N. V. Ayala-Nunez, L. D. I. Turrent and C. R. Padilla, World J. Microbiol. Biotechnol., 2010, 26, 615-621.

13. C. Marambio-Jones and E. M. V. Hoek, J. Nanopart. Res, 2010, 12, 1531-1551.

14. R. J. Griffitt, N. J. Brown-Peterson, D. A. Savin, C. S. Manning, I. Boube, R. A. Ryan and M. Brouwer, Environ. Toxicol. Chem., 2012, 31, 160-167.

15. A. Gupta and S. Silver, Nat. Biotechnol., 1998, 16, 888-888.

16. N. F. Jin, D. Y. Zhang and F. L. Martin, Integr. Biol., 2017, 9, 406-417.

17. P. Marschner, C. H. Yang, R. Lieberei and D. E. Crowley, Soil Biol Biochem, 2001, 33, 1437-1445.

18. E. K. Costello, C. L. Lauber, M. Hamady, N. Fierer, J. I. Gordon and R. Knight, Science, 2009, 326, 1694-1697.

19. C. L. Lauber, M. Hamady, R. Knight and N. Fierer, Appl. Environ. Microbiol., 2009, 75, 5111-5120.

20. M. Wietz, B. Wemheuer, H. Simon, H. A. Giebel, M. A. Seibt, R. Daniel, T. Brinkhoff and M. Simon, Environ. Microbiol., 2015, 17, 3822-3831.

21. H. Li, F. L. Martin and D. Y. Zhang, Anal. Chem., 2017, 89, 3909-3918.

22. P. S. Stewart and J. W. Costerton, Lancet, 2001, 358, 135-138.

23. N. Hoiby, T. Bjarnsholt, M. Givskov, S. Molin and O. Ciofu, Int. J. Antimicrob. Agents, 2010, 35, 322-332.

24. C. G. Mayhall and E. Apollo, Antimicrob. Agents Chemother., 1980, 18, 784-788.

25. M. R. W. Brown, D. G. Allison and P. Gilbert, J. Antimicrob. Chemother., 1988, 22, 777-780.

26. S. M. Ede, L. M. Hafner and P. M. Fredericks, Appl. Spectrosc., 2004, 58, 317-322.

27. O. I. Kalantzi, R. Hewitt, K. J. Ford, L. Cooper, R. E. Alcock, G. O. Thomas, J. A. Morris, T. J. McMillan, K. C. Jones and F. L. Martin, Carcinogenesis, 2004, 25, 613622.

28. J. L. Barber, M. J. Walsh, R. Hewitt, K. C. Jones and F. L. Martin, Mutagenesis, 2006, 21, 351-360.

29. O. Fridman, A. Goldberg, I. Ronin, N. Shoresh and N. Q. Balaban, Nature, 2014, 513, 418-421. 
30. F. L. Martin, J. G. Kelly, V. Llabjani, P. L. Martin-Hirsch, Patel, II, J. Trevisan, N. J. Fullwood and M. J. Walsh, Nat. Protoc., 2010, 5, 1748-1760.

31. M. J. Riding, F. L. Martin, J. Trevisan, V. Llabjani, Patel, II, K. C. Jones and K. T. Semple, Environ. Pollut., 2012, 163, 226-234.

32. J. Li, R. Strong, J. Trevisan, S. W. Fogarty, N. J. Fullwood, K. C. Jones and F. L. Martin, Environ. Sci. Technol., 2013, 47, 10005-10011.

33. M. J. Baker, J. Trevisan, P. Bassan, R. Bhargava, H. J. Butler, K. M. Dorling, P. R. Fielden, S. W. Fogarty, N. J. Fullwood, K. A. Heys, C. Hughes, P. Lasch, P. L. Martin-Hirsch, B. Obinaju, G. D. Sockalingum, J. Sule-Suso, R. J. Strong, M. J. Walsh, B. R. Wood, P. Gardner and F. L. Martin, Nat. Protoc., 2014, 9, 1771-1791.

34. K. A. Heys, M. J. Riding, R. J. Strong, R. F. Shore, M. G. Pereira, K. C. Jones, K. T. Semple and F. L. Martin, Analyst, 2014, 139, 896-905.

35. J. G. Kelly, J. Trevisan, A. D. Scott, P. L. Carmichael, H. M. Pollock, P. L. MartinHirsch and F. L. Martin, J. Proteome Res., 2011, 10, 1437-1448.

36. J. Trevisan, P. P. Angelov, P. L. Carmichael, A. D. Scott and F. L. Martin, Analyst, 2012, 137, 3202-3215.

37. N. Jin, M. Paraskevaidi, K. T. Semple, F. L. Martin and D. Y. Zhang, Anal Chem, 2017, 89, 9814-9821.

38. N. Jin, K. T. Semple, L. Jiang, C. Luo, D. Zhang and F. L. Martin, Analyst, 2018, 143, 768-776.

39. S. N. El Din, T. A. El-Tayeb, K. Abou-Aisha and M. El-Azizi, Int. J. Nanomed., 2016, 11, 1749-1758.

40. A. J. Kora and J. Arunachalam, World J. Microbiol. Biotechnol., 2011, 27, 1209-1216.

41. J. T. H. Jo, F. S. L. Brinkman and R. E. W. Hancock, Antimicrob. Agents Chemother., 2003, 47, 1101-1111.

42. H. Wu, X. Shi, H. Wang and J. Liu, J. Antimicrob. Chemother., 2000, 46, 121-123.

43. J. Trevisan, P. P. Angelov, A. D. Scott, P. L. Carmichael and F. L. Martin, Bioinformatics, 2013, 29, 1095-1097.

44. F. L. Martin, M. J. German, E. Wit, T. Fearn, N. Ragavan and H. M. Pollock, J. Comput. Biol., 2007, 14, 1176-1184.

45. J. Li, G. G. Ying, K. C. Jones and F. L. Martin, Analyst, 2015, 140, 2687-2695.

46. J. C. Betts, P. T. Lukey, L. C. Robb, R. A. McAdam and K. Duncan, Mol. Microbiol., 2002, 43, 717-731.

47. T. Hampshire, S. Soneji, J. Bacon, B. W. James, J. Hinds, K. Laing, R. A. Stabler, P. D. Marsh and P. D. Butcher, Tuberculosis, 2004, 84, 228-238.

48. Z. Movasaghi, S. Rehman and I. U. Rehman, Appl. Spectrosc. Rev., 2008, 43, 134179.

49. M. Drapal, P. R. Wheeler and P. D. Fraser, Microbiology-(UK), 2016, 162, 1456-1467.

50. J. R. Morones, J. L. Elechiguerra, A. Camacho, K. Holt, J. B. Kouri, J. T. Ramirez and M. J. Yacaman, Nanotechnology, 2005, 16, 2346-2353.

51. D. Schnappinger and W. Hillen, Arch. Microbiol., 1996, 165, 359-369.

52. S. R. Connell, C. A. Trieber, G. P. Dinos, E. Einfeldt, D. E. Taylor and K. H. Nierhaus, Embo J., 2003, 22, 945-953.

53. A. M. Fayaz, K. Balaji, M. Girilal, R. Yadav, P. T. Kalaichelvan and R. Venketesan, Nanomed.-Nanotechnol. Biol. Med., 2010, 6, 103-109.

54. C. Jernberg, S. Lofmark, C. Edlund and J. K. Jansson, Microbiology-(UK), 2010, 156, 3216-3223.

55. M. Argast and C. F. Beck, Antimicrob. Agents Chemother., 1984, 26, 263-265.

56. R. W. Bundtzen, A. U. Gerber, D. L. Cohn and W. A. Craig, Rev. Infect. Dis., 1981, 3, 28-37. 
498 57. K. Fuursted, A. Hjort and L. Knudsen, J. Antimicrob. Chemother., 1997, 40, 221-226.

499 58. F. Pomati, A. G. Netting, D. Calamari and B. A. Neilan, Aquat. Toxicol., 2004, 67, 387-396.

501 59. S. B. Levy, J. Antimicrob. Chemother., 2002, 49, 25-30.

502 60. Z. M. Xiu, J. Ma and P. J. J. Alvarez, Environ Sci Technol, 2011, 45, 9003-9008.

503 61. R. Gurbanov, S. N. Ozek, S. Tunçer, F. Severcan and A. G. Gozen, J. Biophotonics, 504 2017, Doi: 10.1002/jbio.201700252.

505 62. R. Gurbanov, N. Simsek Ozek, A. G. Gozen and F. Severcan, Anal Chem, 2015, 87, 506 9653-9661.

507 63. M. Kardas, A. G. Gozen and F. Severcan, Aquat Toxicol, 2014, 155, 15-23.

508 64. S. Kjelleberg, B. A. Humphrey and K. C. Marshall, Appl. Environ. Microbiol., 1983, 46, 978-984.

65. M. J. Riding, J. Trevisan, C. J. Hirschmugl, K. C. Jones, K. T. Semple and F. L. Martin, Environ. Int., 2012, 50, 56-65. 